\title{
Strut-and-tie modelling of short span beams
}

\section{J. Sagaseta ${ }^{1}(\mathrm{PhD})$, R. L. Vollum ${ }^{1}$ (Senior Lecturer)}

1. Imperial College London

NOTICE: this is the author's version of a work that was accepted for the conference proceedings of fib International Symposium 2008. Changes resulting from the publishing process, such as peer review, editing, corrections, structural formatting, and other quality control mechanisms may not be reflected in this document. Changes may have been made to this work since it was submitted for publication. A definitive version was subsequently published in the proceedings of fib International Symposium, Amsterdam 2008, ISBN-13: 978-0-415-47535-8.

Cite this article as :

Sagaseta, J., Vollum, R. L., 2008. Strut-and-tie modelling of short span beams. Proceedings of fib International Symposium 2008, Tailor made concrete structures, Amsterdam, 19-22, ISBN-13: 978-0-415-47535-8. 


\title{
Strut-and-tie modelling of short span beams
}

\author{
J. Sagaseta \& R. Vollum \\ Department of Civil and Environmental Engineering, Concrete Structures Section, Imperial College London; \\ Imperial College Rd, London, SW72BU, United Kingdom
}

\begin{abstract}
In high strength concrete, (HSC) aggregate may fracture leading to relatively smooth cracks and a possible reduction in shear strength. There seems little doubt that shear strength is reduced in beams without stirrups due to aggregate fracture. The influence of aggregate fracture is less clear in beams with stirrups due to a lack of appropriate test data. This paper presents results from a series of 16 beam tests which were carried out at Imperial College London to assess the influence of aggregate fracture on the shear strength of beams with a ratio of shear span to effective depth of either 1.5 or 3.5. This paper focuses on the short span beams. A simple strut and tie model is presented for the analysis of short span beams that is consistent with the design assumptions in EC2. The model is validated with results from 214 tests and is shown to give good predictions of shear strength.
\end{abstract}

\section{INTRODUTION}

High-strength concrete (HSC) is generally used to reduce member sizes and hence the self-weight of the structure. Although many of the advantages of HSC are well known some of the consequences of using HSC, such as its impact on shear strength, are less well understood.

Due to the strong bond between the aggregate and the cement paste in HSC, the aggregate may fracture depending on its type and the concrete strength. Similar problems arise in lightweight aggregate concretes. Aggregate fracture results in a significant reduction in the shear stress that can be transferred through a crack via aggregate interlock. The contribution of aggregate interlock to the shear strength of reinforced concrete beams is uncertain and depends on parameters such as the amount of shear reinforcement and the contribution of arching action for loads applied close to the support.

The general crack pattern and the opening $(w)$ and sliding $(s)$ of the cracks is highly influenced by the ratio of the clear shear span to the effective depth $\left(a_{v} / d\right)$ and the shear reinforcement ratio $\left(\rho_{w}\right)$. This paper focuses on short span beams with $a_{v} / d$ between 1 and 2 although the authors also tested beams with $a / d$ equal to 3.5 where $a$ is the distance between the centrelines of the load and adjacent support.

\section{SHORT SPAN BEAM BEHAVIOUR}

\subsection{General aspects and existing design methods}

In the design of concrete structures, there are many instances where loads are applied within $2 d$ of the supports. Typical examples include corbels, pile caps, hammerhead piers, deep beams and short span beams. Early experimental and analytical work by Kani (1966), Zsutty (1968) and Regan (1971) showed that shear strength increases significantly due to arching action when loads are applied within approximately twice the beams effective depth of the support. Design codes such as BS8110 allow for arching action by increasing the basic shear strength of the concrete by a factor equal to $2 d / a_{v}$. EC2 adopts the alternative approach of reducing the component of shear force due to loads applied within $2 \mathrm{~d}$ of the support by a factor $\beta=a_{v} / 2 d$ as shown in Figure 1 .

The behaviour of short span beams is significantly different from normal and deep beams. In short span beams the diagonal crack, which generally runs in a straight line between the inner edges of the loading and bearing plates (Fig. 1), forms independently of the flexural cracks and remains stable until failure as reported by Regan (1971). The shear strength and ductility can be enhanced by adding transverse reinforcement. Vertical stirrups have been shown to be more efficient than horizontal links for $a_{v} / d$ between 1 and 2 . Design codes usually recom- 
mend that horizontal stirrups are used in beams with $a_{v} / d$ less than 0.5 . Vertical stirrups increase the shear strength if they cross the diagonal shear crack and are considered effective for design purposes if placed within the central three quarters of the clear shear span.

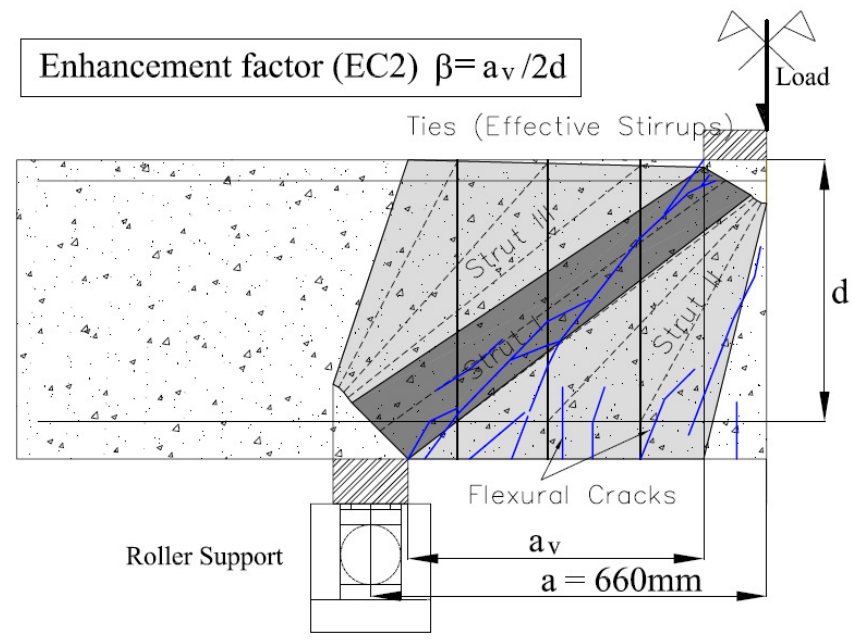

Figure 1. Typical crack pattern and load paths on a short span beam (Beam AL3 tested at Imperial College, London)

The authors examined a database of 150 short span beams with vertical stirrups tested by 12 different researchers including the authors and found (Fig. 2) that the performance of the simplified design method in EC2 for short span beams was highly dependent on the stirrup index $\left(S I=n . A_{s w} f_{y} / b / h / f_{c}\right)$ where $n=$ number of effective stirrups; $A_{s w}=$ area of stirrups; $f_{y}$ $=$ yield strength of stirrups; $b=$ width; $h=$ height; and $f_{c}=$ concrete cylinder strength. The EC2 method becomes less conservative as $S I$ increases as shown in Figure 2.

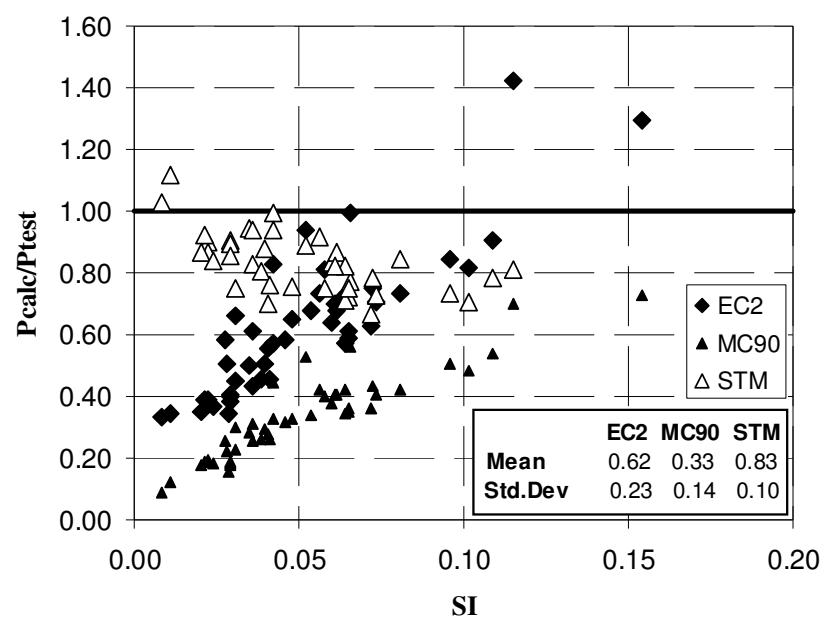

Figure 2. Pcalc/Ptest ratio for the simplified EC2 method, MC90 and STM in relation with the stirrup index $(S I)$, beams with vertical stirrups and $a_{v} / d$ between 1 and 2 .

Note: experimental results from Walraven \& Lehwalter (1994), Regan (1971), Oh \& Shin (2001), Tan et al. (1995), Tan et al. (1997), Kong et al. (1970), De Pavia \& Siess (1965), Vollum \& Tay (2001), Clark (1951), Sarsam \& Al-Musawi (1992), Kong \& Rangan (1998), Sagaseta \& Vollum (2007, unpubl.).
The authors also investigated the accuracy of equation (1) below which was recommended by Schlaich and Schafer (1991) and subsequently included in Model Code MC90. Figure 2 shows that the predictions of equation (1) follow a similar trend to the method in EC2 but the results are more conservative. It is noteworthy that equation (1) only relates $F_{w}$ to $a / z$.

$$
F_{w}=\frac{2 a / z-1}{3-N_{S d} / F} F
$$

where $F_{w}=$ shear carried by the stirrups; $F=$ total shear; $a=$ distance between centre load points; $z=$ lever arm taken as 0.9 times the effective depth $(d)$; and $N_{S d}=$ axial tension (positive for tension).

\subsection{Strut-and-tie modelling}

EC2 permits short span beams to be designed with the strut-and-tie method (STM) as an alternative to reducing the design shear force by $\beta$, which raises the question of which method is most realistic. The sensitivity of the predictions of these two methods to geometrical and material properties differs significantly. The STM is a transparent approach but various assumptions need to be made regarding the geometry of the nodes, the width of the struts and the concrete strength. The predictions of strut-and-tie models are dependent on these assumptions in addition to geometrical parameters such as the length of bearing plates and the concrete cover to the main tensile reinforcement.

The strut-and-tie model for short span beams presented in this paper is consistent with the recommendations for STM made in EC2. The model is applicable to symmetrically loaded beams with either one or two point loads. The design equations given in this paper are valid for beams with stirrups. The equations can be easily adapted for the analysis of beams without stirrups. The bearing stress under the loading and supporting plates were limited to $v f_{c d}$ and $0.85 v f_{c d}$ respectively as recommended in EC2 for compression-compression (CC) and compression-tension (CT) nodes in strut-and-tie models.

The load paths in the model, which are shown in Figure 1, consist of a direct strut (Strut I) and a truss system (Strut II-Stirrups-Strut III). In order to simplify the problem of internal statical indeterminacy, the stirrups were assumed to yield at failure. This assumption is justified by the experimental work of Clark (1951), Regan (1971), and the authors amongst others for beams with SI up to at least 0.1 . Only the direct strut in Figure 1 is present in beams without shear reinforcement.

The strength of strut $\mathrm{I}$ is affected by the diagonal crack and transverse tensile strains induced by the stirrups crossing it. Strut II, which is equilibrated by the stirrups, is affected by flexural cracks that de- 
crease its strength. The third compressive stress field, Strut III, is fan shaped like Strut II, but the concrete in this region is essentially uncracked. The geometry of the strut-and-tie model is defined in Figure 3 . The orientation of strut III is defined below in equation (2) in terms of the angles to the horizontal $\phi_{i}{ }_{i}$ made by lines drawn from the top of each stirrup $i$ to the bottom node as shown in Figure 3.

$\cot \phi_{i}^{\prime}=\frac{a_{v}+l_{b}-\frac{2(n-i)+1}{2 n} \cdot(1-\lambda) \cdot l_{b}-S_{i}+\frac{l_{t}}{2} \cdot n_{l p}}{h-2 c+\frac{2(n-i)+1}{2 n} \cdot(1-\lambda) \cdot 2 c-C_{i}^{\prime}}$

where $n_{l p}$ equals the number of loading points at the top of the beam which is assumed to be either 1 or 2 . All the other terms in equation (2) are defined in Figure 3 . The only unknown parameter in equation (2) is $\lambda$ which is the proportion of the total load taken by the direct strut. If the parameter $\lambda$ is known the entire geometry of the strut-and-tie model in Figure 3 is defined, including the size of the nodes.

In order to simplify the model, the top boundary of Strut III was assumed to be linear so that $C_{i}$ could be obtained easily from horizontal equilibrium at the top node. This assumption has no significant effect on the angle $\dot{\phi}_{i}$.

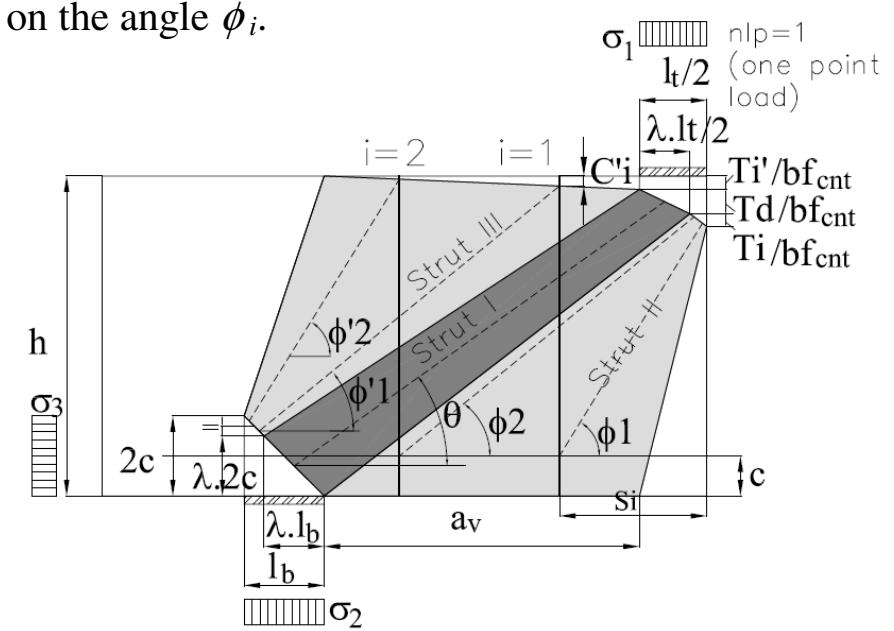

Figure 3. Geometry of strut-and-tie model for short span beams with vertical stirrups (example for $n_{l p}=1$ and $n=2$ )

The tensile force in the reinforcement at the bottom node $(T)$ can be divided into two components $T=T_{\mathrm{i}}$ $+T_{\mathrm{d}}$, where $T_{\mathrm{i}}$ is the force transmitted by the indirect strut II and $T_{\mathrm{d}}$ is force transmitted by the direct strut I. Both components are given by the equations (3) and (4).

$$
\begin{aligned}
& T_{i}^{\prime}=T_{S i} \cdot \sum_{1}^{n} \cot \phi_{i}^{\prime} \\
& T_{d}=\frac{\lambda}{1-\lambda} \cdot \cot \theta \cdot \sum_{1}^{n} T_{S i}
\end{aligned}
$$

applied in the beam $(P)$ can be written in terms of $\lambda$ and $T_{S i}$ as in equation (5).

$P=\frac{2 \sum_{1}^{n} T_{S i}}{(1-\lambda)}$

Equation (6) defines the angle $\theta$ of the centreline of the direct strut to the horizontal. All the geometrical parameters in equation (6) are known and only the proportion of load taken by the direct strut $(\lambda)$ and the total tensile force at the bottom node $(T)$ need to be determined.

$$
\cot \theta=\frac{a_{v}+\frac{l_{b} \lambda}{2}+\frac{l_{t} \lambda}{4} \cdot n_{l p}}{h-c \lambda-\left(\frac{T_{i}^{\prime}+T_{d} / 2}{b f_{c n t}}\right)}
$$

where $f_{\text {cnt }}$ corresponds to the concrete strength at the top node which is taken as $v \cdot f_{c d}$ as recommended in EC2.

The angle $\theta$ can be expressed in terms of $\lambda$ by substituting equations (2, 3 and 4) into (6). So far only geometric relationships and equilibrium at nodes have been considered. The coefficient $\lambda$ depends on the assumed failure mode.

Two failure modes were considered in the estimation of the ultimate load; namely crushing of the direct strut and failure at the bearing plates. The ultimate load was taken as the lowest value corresponding to these modes of failure. The critical failure mode in the majority of the beams studied was crushing of the direct strut.

The strength of the direct strut is governed by the product of its cross-sectional area and the effective concrete strength. In general good predictions were obtained using the effectiveness factor $0.6 v$ defined in EC2, where $v=\left(1-f_{c k} / 250\right)$. The effectiveness factor accounts for the reduction in concrete compressive strength due to transverse tensile strain. Good predictions were obtained for the ultimate load if the width of the strut $\left(w_{\text {strut }}\right)$ was calculated from the geometry of the bottom node, see equation (7).

$w_{\text {strut }}=\lambda l_{b} \sin \theta+2 c \lambda \cos \theta$

Limiting the stress in the strut to $v f_{c d}$ and imposing horizontal equilibrium at the bottom node leads to equation (8), which relates $\theta$ and $\lambda$. The parameters $\theta$ and $\lambda$ are solved iteratively from the system of non-linear equations (2-6 and 8).

$$
\frac{\lambda}{1-\lambda} \cdot \sum_{1}^{n} T_{S i}=\left(\lambda l_{b} \sin ^{2} \theta+c \lambda \sin 2 \theta\right) \cdot b v f_{c d}
$$

where $T_{S i}$ is the tensile force carried by each stirrup assuming it has yielded $\left(T_{S i}=A_{s w} f_{y}\right)$. The total load 


\section{VALIDATION OF ANALYTICAL MODELS}

\subsection{Experimental evidence}

The authors have validated their model against a database of 214 beams of which 150 had vertical stirrups. One of the difficulties in developing the database was that important information was often not reported. Firstly, although the crack pattern was described in detail in most cases, information was seldom if ever given on either the type of aggregate used or whether it had fractured. Secondly, many authors omitted to give the size of the bearing plates, which is required in the STM. Thirdly, some beam tests have been carried out using rollers for the supports. Beams loaded/supported using rollers were excluded from the database to avoid possible deviations due to bearing failure under the rollers. If the strut-and-tie model presented in this paper is used for assessing the strength of beams with rollers, an equivalent bearing plate length can be estimated assuming a value for the dispersion angle $(\alpha)$ from the centreline of the roller. Acceptable results were obtained with $\alpha=45^{\circ}$. Fourthly, little information was reported on the relative displacements at cracks during loading. Crack widths are often reported but information is not usually given on crack sliding.

A series of 8 short span beams were tested at Imperial College London to assess the influence on shear strength of aggregate interlock and aggregate fracture. The beams were simply supported and loaded at mid-span. The beams had a rectangular cross section $500 \mathrm{~mm}$ high and $135 \mathrm{~mm}$ wide with two layers of two H25 longitudinal reinforcement bars $(d=437.5 \mathrm{~mm})$. The loading plate was $210 \times$ $135 \mathrm{~mm}$. One set of 4 beams (ALO-AL4) was cast with limestone aggregate, which fractured completely at cracks. The remaining 4 beams (AG0AG4) were identical to set AL but were constructed with normal gravel aggregate. In beams AG the crack only went through a small proportion of the aggregate. Beams A0 had no shear reinforcement whilst the amount of stirrups was progressively increased in beams A2-A4 from two to four T8 stirrups per shear span.

The beams were intended to have similar concrete strengths of around $60 \mathrm{MPa}$ but the concrete delivered by the concrete supplier had concrete strengths; $f_{c m}=68.4 \mathrm{MPa}$ and $80.2 \mathrm{MPa}$ for $\mathrm{AL}$ and $\mathrm{AG}$ beams respectively. Failure was encouraged to develop in the left hand shear span by decreasing the length of the left hand bearing plate by $37.5 \%\left(l_{b, l e f t}=125 \mathrm{~mm}\right.$, $\left.l_{b, r i g h t}=200 \mathrm{~mm}\right)$. This change in the size of the bearing plate results in a $20 \%$ increase in strength according to the STM or $8 \%$ if the EC2 simplified method is applied. Of the 8 beams tested, 6 failed in the shear span with $a_{v} / d$ of 1.12 and only two (AG4, AL2) on the span with $a_{v} / d$ of 1.04 as expected.

All the beams failed in shear but the flexural reinforcement yielded in specimens AG3-4. The main diagonal shear crack formed at around $30 \%$ of the ultimate load prior to flexural cracking. The loaddeflection curve was almost linear until failure where the main diagonal crack expanded to the top inner edge of the loading plate.

\subsection{Predictions of STM and EC2 approaches}

Table 1 summarizes the predictions obtained from the STM and EC2 models for the beams tested. The material factors of safety were taken as 1.0 in the analysis. The STM seem to give better predictions overall but the strength of beams AG0 with no stirrups was significantly over predicted. This is possibly due the effective strength of the concrete in the strut being overestimated. In the EC2 simplified approach for short beams with no stirrups, the shear strength $\left(V_{c}\right)$ is estimated using an empirical equation. The term $V_{c}$ is neglected in the EC2 truss model for beams with stirrups. A total of 64 short beams without stirrups (Mathey \& Watsein 1963, Moody et al. 1954, Walraven \& Lehwalter 1994, Placas 1969, Vollum \& Tay 2001, Ortiz 1993, Tan et al. 1997, Oh \& Shin 2001 and Clark 1951) were analysed. Average values of 0.79 and 0.52 were obtained for $P_{\text {calc }} / P_{\text {test }}$ using the STM and EC2 approaches respectively. The standard deviations were 0.16 (STM) and 0.08 (EC2).

Table 1. Summary of short beams tested.

\begin{tabular}{ccccc}
\hline Beam & $\begin{array}{c}\rho_{v}{ }^{*} \\
{[\%]}\end{array}$ & $S I$ & $\begin{array}{c}P_{\text {cald }} / P_{\text {test }} \\
(\mathrm{STM})\end{array}$ & $\begin{array}{c}P_{\text {cald }} / P_{\text {test }} \\
(\mathrm{EC} 2)\end{array}$ \\
\hline AG0 & 0 & 0 & 1.28 & 0.53 \\
AG2 & 0.22 & 0.020 & 0.79 & 0.35 \\
AG3 $^{* *}$ & 0.34 & 0.031 & 0.69 & 0.45 \\
AG4 $^{* *}$ & 0.45 & 0.041 & 0.66 & 0.56 \\
\multicolumn{7}{c}{ Mean / St.Dev. } & $\mathbf{0 . 8 6 / 0 . 1 7}$ & $\mathbf{0 . 4 7 / 0 . 0 9}$ \\
AL0 & 0 & 0 & 1.04 & 0.45 \\
AL2 & 0.22 & 0.024 & 0.76 & 0.37 \\
AL3 & 0.34 & 0.036 & 0.87 & 0.61 \\
AL4 & 0.45 & 0.048 & 0.71 & 0.65 \\
\multicolumn{7}{c}{ Mean / St.Dev. } & $\mathbf{0 . 8 5 / 0 . 1 4}$ & $\mathbf{0 . 5 2 / 0 . 1 3}$ \\
\hline
\end{tabular}

$* \rho_{v}(\%)=\mathrm{A}_{\mathrm{sw}} /(\mathrm{ab}) \times 100$

** Longitudinal steel yielded

For short span beams with stirrups, the STM predictions seemed to be more realistic than those given by the simplified approach suggested in EC2 as shown in Figures 2 and 4. In order to assess the range of validity of the models, beams with $a_{v} / d$ lower than 1 and between 2-2.5 were also investigated. Figure 4 shows that the authors STM is unsuitable for beams with $a_{v} / d$ greater than 2 . The model is also rather conservative for beams with $a_{v} / d$ less than 0.75 . Figure 4 shows that the influence of $a_{v} / d$ on the accuracy of the predictions of the EC2 model is opposite to that for the STM.

The large scatter shown in Figure 4, especially for the EC2 model, is due to variations in SI. In the 
STM model, the percentage of load carried by the direct strut $(\lambda)$ decreases as SI increases. Analysis shows that the accuracy of STM almost independent of $S I$ and hence the overall scatter in $\mathrm{P}_{\text {calc }} / \mathrm{P}_{\text {test }}$ is less for the STM than for the EC2 model with $a_{v} / d$ between 1 and 2.

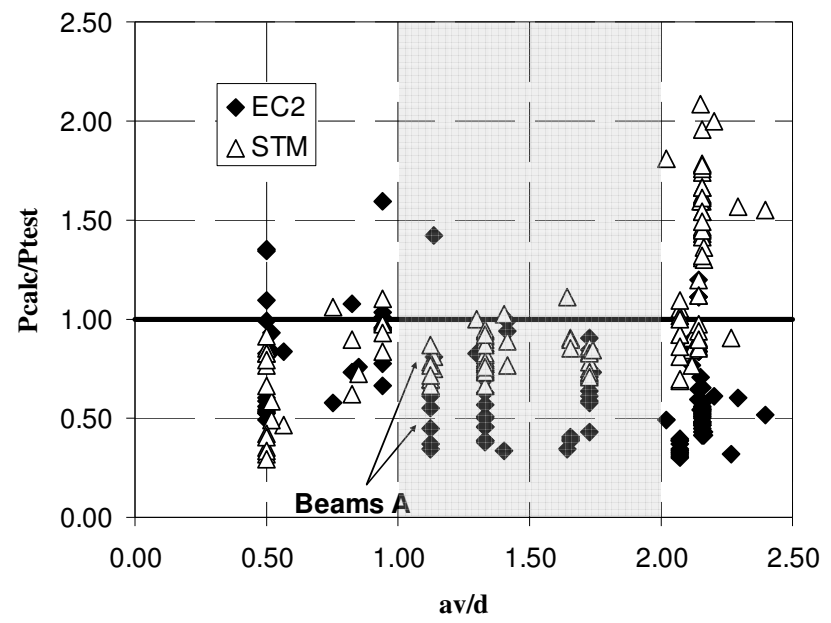

Figure 4. $P_{\text {calc }} / P_{\text {test }}$ variation with $a_{v} / d$ for STM and EC2 approaches (beams with stirrups).

\section{INFLUENCE OF AGGREGATE FRACTURE}

\subsection{Results for short span beams}

The analysis of beams A suggests that the strength of the short span beams tested was not significantly influenced by the fracture of the aggregate. The relative displacements of the main diagonal crack were monitored in the left shear span $\left(a_{v} / d=1.12\right)$ at two points on each side of the beam. Two crosses of Demec gauge studs were placed on the north side of the beam. Two crosses of LVDT's were placed on the south side as shown in Figure 5. Both types of measurement gave readings which were consistent with each other and with visual measurements of crack width obtained with an optical crack microscope. The Demec gauge readings were reliable but had the disadvantages that the readings were discontinuous and could not be safely taken near failure. The orientation of the main diagonal crack was similar in the gravel and limestone specimens. The inclination of the critical shear crack became closer to the inclination of the direct strut in the STM as the number of stirrups was increased in both the $A G$ and AL beams.

The crack opening $(w)$ was predominant over sliding $(s)$ up to failure in all the beams, as shown in Figure 6. The ratio $\delta w / \delta s$ was around 3 up to the peak load in all the specimens. Once the beam failed, crack sliding became active and the $\delta w / \delta s$ ratio reduced to 1 . In beams AG4 and AL2, which failed on the right shear span $\left(a_{v} / d=1.04\right)$, the diagonal crack on the left span started closing after the ultimate load was reached, see Figure 6. The large values of crack opening compared with crack sliding shown in Figure 6 , suggests that little shear was transmitted through the main diagonal crack by means of aggregate interlock action in the authors' beams with $\mathrm{a} / \mathrm{d}=1.5$. The authors' push-off tests suggest that the ratio between the crack opening and sliding $\delta w / \delta s$ would have been closer 1 for significant shear to be transferred across the diagonal crack.

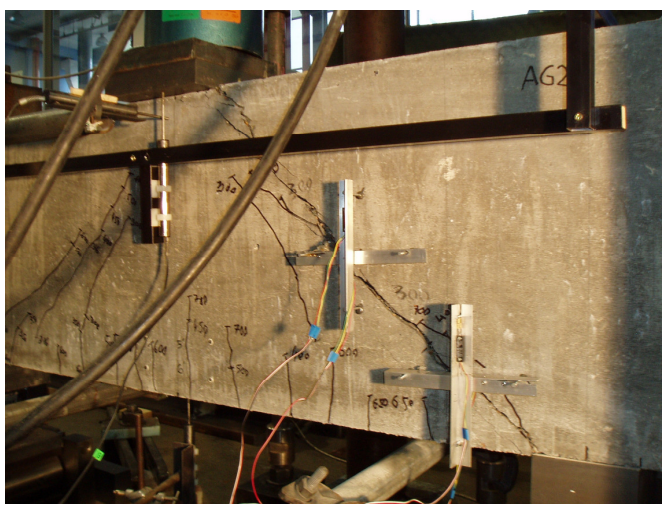

Figure 5. Monitoring crack relative displacements of main diagonal crack of beams A (LVTDs crosses, south side).

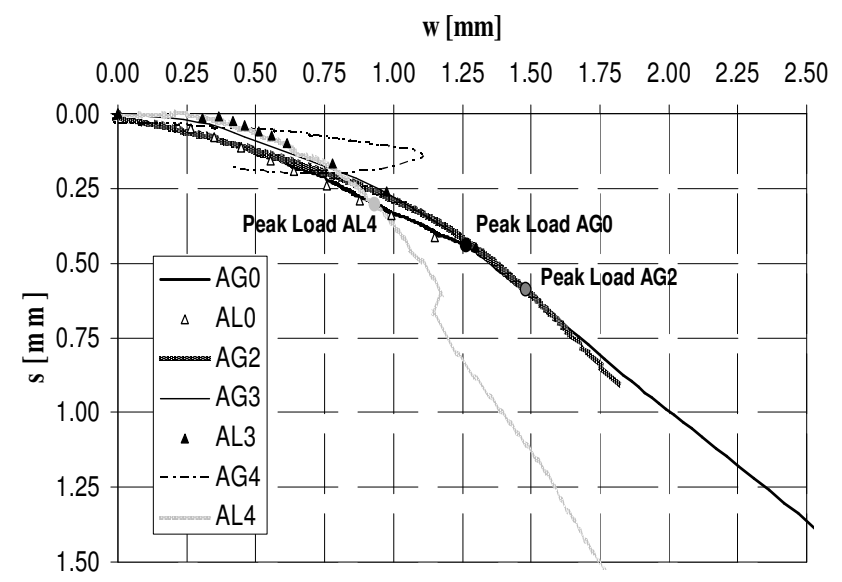

Figure 6. Crack opening and sliding of main diagonal crack on the left hand shear span $\left(a_{\sqrt{ }} / d=1.12\right)$ of beams A.

Analytical estimations of the shear transmitted through a crack, which is $1-1.5 \mathrm{~mm}$ wide, give very low values of shear stress regardless the analytical model applied. For the limestone aggregate concrete used for beams AL and assuming $w=1.2 \mathrm{~mm}$ and $s=$ $0.4 \mathrm{~mm}$ the shear transmitted according to Bazant \& Gambarova (1980) model is only 0.5MPa. Other models such as Walraven \& Reihardt (1981) predict values close to zero. Some additional experimental evidence has been obtained from Push-off tests performed by the authors at Imperial College London, using limestone aggregate. As an order of magnitude, cracks $1.5 \mathrm{~mm}$ wide with similar reinforcement ratio as beam AL4, were capable of transmitting shear stresses up to $3 \mathrm{MPa}$, but the slip required was $6 \mathrm{~mm}$. 


\subsection{Results for slender beams}

The influence of aggregate fracture was also examined for beams where arching action was not predominant. Slender beams, with $a / d$ equal to 3.5 , were tested with and without shear reinforcement. The cross section and type of aggregate were identical as for beams A. The reduction in strength due to aggregate fracture was found more significant for those beams without stirrups. The experimental results had a good correlation with Regan et al. (2005) findings for similar beams.

Ongoing experimental work is focused on slender beams with different shear reinforcement ratios. Four beams have been tested with a point of contraflexure in order to avoid shear contribution at the compression head. The ratios of $\delta w / \delta s$ at the main shear crack were significantly different than in the short span beam series A and the aggregate interlock action seemed to have a more important role.

\section{CONCLUSIONS}

A simple strut-and-tie model is proposed in this paper for short span beams that is consistent with the recommendations in EC2 for STM. The model gives good predictions of the ultimate strength. The shear reinforcement is assumed to yield at failure, which is reasonable for beams with stirrup indexes $S I$ below 0.1 . The simplified design method in EC2, in which the design shear force is reduced by a factor $\beta=a_{v} / 2 d$, gives good predictions for SI between 0.05 and 0.1 but is unduly conservative for lower values of $S I$.

Unfortunately, most authors do not report details of the aggregate type used in their tests or whether it fractured. However, the experimental work presented in this paper suggests that aggregate fracture does not have a significant effect on the shear strength of short span beams with a/d equal to 1.5 since crack opening was predominant over sliding in the main diagonal crack. The influence of aggregate fracture was found to be more significant in slender beams, particularly for beams without shear reinforcement.

Future code revisions should relate any reduction in shear strength due to aggregate fracture to the $a / d$ ratio which affects the relationship between crack opening and slip. Further experimental work is required to investigate the influence of $a / d$ and the shear reinforcement ratio on the shear strength of beams in which aggregate fractures.

\section{ACKNOWLEDMENTS}

The authors would like to thank the staff of the Concrete Structures Laboratory at Imperial College and acknowledge the financial support of the Fundación Caja Madrid.

\section{REFERENCES}

Bazant, Z.P \& Gambarova, P.G. 1980. Rough crack models in reinforced concrete. ASCE-Journal of Structural Engineering, 106 (4): 819-842.

Clark, A.P. 1951. Diagonal tension in reinforced concrete Beams. Journal of the American Concrete Institute, 23 (2): 145-156.

De Pavia, H.A \& Siess, C.P. 1965. Strength and behavior of deep beams in shear. Journal of the Structural Division, Proceeding of the American Society of Civil Engineers, 91 (ST5): 19-45.

Kani, G.N. 1966. Basic facts concerning shear failure. Journal of the American Concrete Institute, No.63-32: 675-691.

Kong, F.K, Robins, P.J. \& Cole, D.F. 1970. Web reinforcement effects on deep beams. ACI Journal, 66-73: 1010-1017.

Kong, Y.L \& Rangan, B.V. 1998. Shear strength of highperformance concrete beams. ACI Structural Journal, 94 (6): 677-688.

Mathey, R.G \& Watsein, D. 1963. Shear strength of beams without web reinforcement containing deformed bars of different yield strengths. ACI Journal, 60 (2): 183-207.

Moody, K.G, Viest, I.M, Ester, R.C, Hognestad, E. 1954. Shear strength of reinforcement concrete beams Part 1- Test simple beams. ACI Journal, 26 (4): 317-332.

Oh, J.K. \& Shin, S.W. 2001. Shear strength of reinforced highstrength concrete deep beams. ACI Structural Journal, 98 (2): 164-173.

Placas, A. 1969. Shear strength of reinforced concrete beams. Ph.D Thesis, Civil Engineering Department, Imperial College of Science and Technology, London.

Regan, P.E. 1971. Shear in reinforced concrete - An analytical study. Report to the Construction Industry Research and Information Association - CIRIA. London: CIRIA.

Regan, P.E, Kennedy-Reid, I.L, Pullen, A.D, Smith, D.A. 2005. The influence of aggregate type on the shear resistance of reinforced concrete. The Structural Engineer, 6th December 2005: 27-32.

Reyes de Ortiz, I. 1993. Strut and tie modelling of reinforced concrete short beams and beam-column joints. Ph.D Thesis, University of Westminster, London.

Sarsam, K.F \& Al-Musawi, J.M. 1992. Shear design of highand normal strength concrete beams with web reinforcement. ACI Structural Journal, 89 (6): 658-664.

Schlaich, J. \& Schafer, K. 1991. Design and detaling of structural concrete using strut-and-tie models. The Structural Engineer, 69 (6): 113-125.

Tan, K.H., Kong, F.K., Teng, S. \& Guan, S. 1995. Highstrength concrete deep beams with effective span and shear span variations. ACI Structural Journal, 92 (4): 395-405.

Tan, K.H., Kong, F.K., Teng, S. \& Weng, L.W. 1997. Effect of web reinforcement of high-strength concrete deep beams. ACI Structural Journal, 94 (5): 572-582.

Vollum, L.R \& Tay, U.L. 2001. Strut and tie modelling of shear failure in short-span beams. Concrete Communication Conference 2001, London.

Walraven, J.C \& Reinhardt, H.W. 1981. Theory and experiments on the mechanical behaviour of cracks in plain and reinforced concrete subjected to shear loading. Heron (ed.), Concrete mechanichs, part A. Delft: Heron.

Walraven, J.C. \& Lehwalter, N. 1994. Size effects in short beams loaded in shear. ACI Structural Journal, 91 (5): 585593.

Zsutty, T.C. 1968. Beam shear strength prediction by analysis of existing data. ACI Journal, 65: 943-951. 